\title{
Self-perceived and reported mental health in older adults
}

\author{
Tomás Zamora-Iniesta ${ }^{1}$, Pedro Castell-Gallud ${ }^{2}$, Visitación Fernández-Fernández ${ }^{3}$, Maravillas Castro-Sáez ${ }^{3}$, \\ José-Luís Vicente-Escudero ${ }^{4}$, and Concepción López-Soler ${ }^{5, *}$ \\ 1 Health Specialist in Family and Community Medicine.University of Murcia (Spain) \\ 2 Psychological Instrumentation Section - ACTI. University of Murcia(Spain) \\ 3 Associate Professor. University of Murcia (Spain) \\ 4 Máster General Health Psychology. University of Murcia (Spain) \\ 5 Clinical Professor Hospital V. Arrixaca-University of Murcia (Spain)
}

\begin{abstract}
Título: Salud mental autopercibida e informada en personas mayores. Resumen: Son numerosos los trabajos que evalúan la salud mental de las personas mayores, pero relativamente escasos los que lo hacen desde una perspectiva multi-informante. En este trabajo se analizaron las discrepancias en la autopercepción y la percepción que tienen otros de la salud mental de las personas mayores, en dos franjas de edad, diferenciando por sexos, lugar de residencia y se analizaron las relaciones entre diferentes escalas que miden psicopatología y competencias psicosociales.

Se empleó una muestra de 288 personas mayores entre 60-95 años (154 mujeres, 53.47\%) pertenecientes a 12 municipios de la Región de Murcia, y se empleó el cuestionario OlderAdultSelf-Report (OASR) para medir la psicopatología de las personas mayores y el instrumentoOlderAdultBehaviorChecklist (OABCL) para conocer la percepción de la familia de estos problemas.

Los resultados reflejan que existen diferentes percepciones de la salud mental entre personas mayores y sus familiares, que empeoran al aumentar la edad, la situación de riesgo psicosocial y el género femenino. Esto refleja la necesidad de desarrollar protocolos de tratamiento específicos para cada género y situación de riesgo psicosocial, con el fin de atender las necesidades diferenciales de salud mental de las personas mayores.
\end{abstract}

Palabras clave: Salud mental. Personas mayores. OASR. OABCL. Géne-

\begin{abstract}
Several studies assess mental health in older adults, but relatively few do so from a multi-informant perspective. In this work, discrepancies in self-perception and third-person perception of the mental health of older adults were analyzed in two age groups and differentiated by sex and place of residence. Relationships between different scales that measure psychopathology and psychosocial competencies were also analyzed. A sample of 288 older people aged between 60-95 years old (154 women, $53.47 \%$ ) belonging to 12 municipalities in the Region of Murcia was employed, and the Older Adult Self-Report (OASR) questionnaire was used to measure the psychopathology of older people and the Older Adult Behavior Checklist (OABCL) instrument to find out the family's perception of these problems.

Outcomes show different perceptions of mental health among older people and their families, which worsen with increasing age, psychosocial risk status and female gender. This reflects the need to develop specific treatment protocols for each gender and psychosocial risk situation, in order to address the differential mental health needs in older people.
\end{abstract}

Keywords: Mental Health. Elderly. OASR. OABCL. Gender.

\section{Introduction}

Population aging is increasing, and the proportion of people over 60 years of age has risen considerably, and according to the World Health Organization (WHO, 2017), at the global level, the elderly population will double compared to what it is at present. In absolute terms, it is expected that by 2050 there will be 2 billion people over the age of 60 and 400 million over 80 (Lang, 2010, Valdés et al., 2017). The aging process involves changes in physical and mental health, bringing with it a greater amount of problems. Even in very different socioeconomic cultures, the predictive factors for suffering mental illnesses such as depression are comparable (Sengupta and Benjamin, 2015). Population aging, added to a direct relationship between increasing age and the presence of mental disorders, makes early detection and treatment of the population essential (Black et al., 2019; Gázquez- Linares et al., 2008). The WHO reports that $25 \%$ of those over 65 have a mental disorder (WHO, 2015, 2017) with depression and anxiety being most frequent (Ausín et al., 2017; Charney et al., 2003). The prevalence of having suffered at least one

* Correspondenceaddress [Dirección para correspondencia]: Concepción López-Soler. Faculty of Psychology. University of Murcia (Spain). E-mail: clopezs@um.es

(Article received: 7-5-2021, revised: 14-5-2021, accepted: 20-6-2021) psychopathological disorder throughout life in older people has been studied, observing $45.7 \%$ of older people did so (34.7\% men; $53.5 \%$ women), and of all disorders, the most common was depression, with a prevalence of $26.5 \%(16.6 \%$ men; 33.6\% women) (Ritchi et al., 2004). Other more recent studies report similar results indicating the prevalence may be $40.12 \%$, with women more affected by anxiety-depressive disorders and men by substance use problems (Ausín et al, 2017).

There are sociodemographic factors that qualify the overall results; It has been found that the predictive factors of depression in the elderly were financial difficulties $(O R=$ 4.52), self-perceived health $(O R=.08)$, social support network $(O R=.05)$, grief $(O R=2.70)$, living in urban environments $(O R=1.67)$, being a woman $(O R=1.47)$, advanced age $(O R=2.19)$, living in a nuclear family $(O R=3.64)$, lower education levels $(O R=1,99)$, being more alone $(O R=1.17)$, functional impairment $(O R=11.80)$ and cognitive impairment $(O R=3.39)$ (Baiyewu et al., 2015; Curran et al., 2019; Sengupta et al., 2015). Other studies showed that $55.8 \%$ of those over 60 suffered from depressive symptoms. These were significantly higher in women $(61.93 \%)$ than men $(49.75 \%)$ observing that women were $61 \%$ more likely to suffer from depression than men $(O R=1.25)$. In addition, older people who presented comorbidity with physical illnesses were $67 \%$ more likely to suffer from depression (OR 
$=1.67$ ) than those without physical problems (Hoang et al., 2020; Yadav et al., 2020).

In Spain, the most common mental disorders observed in the elderly are anxiety and somatoform disorders (42.7\%), followed by stressful situations, mood disorders (affective) $(30.1 \%)$ and organic mental disorders (14.8\%). (GázquezLinares et al., 2008). Differences have been found between men and women in the total prevalence of depression, greater presence in women than men $(26.5 \%$ men; $43.1 \%$ women) (Kronfly-Rubiano et al., 2015). Other studies suggest the prevalence of depression could reach $35.8 \%$ in the elderly, higher in women $(O R=2.98)$ (Damián et al., 2012) and the prevalence of anxiety could reach $20.8 \%$ (Cisneros and Ausín, 2018).

There are various questionnaires to assess psychopathology and psychosocial competencies in people over 60 years of age. Assessment is complicated due to the cognitive difficulties that older people can present and that makes it necessary to gather data from other informants such as spouses, children or caregivers. However, a meta-analysis only shows small agreement between third-party reports and self-reports of older people (Achenbach, et al., 2005). Despite this, as Mindt, et al. (2019), there is currently a scarcity of assessment instruments that are common between cultures, linguistically diverse and that measure psychopathological constructs and psychosocial competencies in people specifically over 60 years of age. To overcome this limitation, the Achenbach questionnaires are instruments capable of evaluating the clinical, sociodemographic and psychosocial competencies of older people, and it has recently been reported that the empirical syndromes of the Older Adult Self-Report (OASR) questionnaire (Achenbach et al., 2004), are generalizable to 19 different societies in America, Europe and Asia (Ivanova et al., 2020). The existing correlations between the empirical syndromes measured by the questionnaire have a positive and high magnitude among them, the highest correlation being the irritability / disinhibition syndrome with thought problems $\left(r_{x y}=.90\right)$, thought problems with anxiety / depression $\left(r_{x y}=.86\right)$, and memory / cognition problems with functional impairment $\left(r_{x y}=.82\right)$ (Ivanova et al., 2017). Other studies find highest correlations between the total problems with anxiety / depression $\left(r_{x y}=.876\right)$ and somatic complaints $\left(r_{x y}=.751\right)$, besides functional impairment $\left(r_{x y}=\right.$ $.761)$, memory problems / cognition $\left(r_{x y}=.730\right)$, thought disorders $\left(r_{x y}=.818\right)$ and irritability $\left(r_{x y}=.735\right)$ (de Oliveira et al., 2017). In addition, the Older Adult Behavior Checklist (OABCL) questionnaire (Achenbach et al., 2004), developed in parallel to the OASR, and which reports the mental health of the elderly by third parties, shows moderate-high associations with scales from other questionnaires that measure the neuropsychological status of the elderly and geriatric depression (Brigidi et al., 2010). Both questionnaires have shown adequate internal consistency in international studies, $\alpha=.89$ for OASR (Ivanova et al., 2017) and $\alpha=.91$ for OABCL (Achenbach et al., 2004).

The aims of this study are (1) to know the prevalence of psychopathological alterations and psychosocial competences that people over 60 years of age present and the perception of their partners or caregivers according to age and gender. (2) Analyze relationships between clinical problems in self-reports and hetero-reports. (3) Analyze psychopathological differences and psychosocial competencies based on gender and place of residence.

\section{Method}

\section{Participants}

For this cross-sectional study, a sample of the general population of 288 elderly people aged between 60 and 95 years old was selected by incidental sampling, with a mean age of 77 years $(S . D .=8.88)$ in the total sample $(154$ women, $53.47 \%)$. The mean age for women is $77.5($ S.D. $=.709)$, and for men 76.1 (S.D. $=1.086$ ).

Subjectsresided in theRegion of Murcia, particularly in Murcia capital (44.4\%), Torres de Cotillas (2.7\%), Cartagena (8.4\%), Águilas (9.8\%), Molina de Segura (5.3\%), Alhama de Murcia (1.8\%), Abarán (8.4\%), Abanilla (0.9\%), Ceutí (5.3\%), Cieza (0.9\%), El Palmar (3.6\%), and Ribera de Molina $(8.4 \%)$.

$38.7 \%$ of subjects lived in a residence and $61.3 \%$ in private homes. $22 \%$ of the sample was between 60 and 69 years old, 39\% between 70 and 79 years old, and 39\% were above 80 years old.

More than $50 \%$ of the sample $36.6 \%$ men; $60.4 \%$ women) had no primary school studies, $45 \%$ of the sample were married and living with their spouse (62\% men; $37.7 \%$ women), followed by a $38 \%$ in widowhood (14.1\% men; $48.7 \%$ women) (Table 1$)$.

Table 1

Frequencies, educational level and marital status.

\begin{tabular}{|c|c|c|c|c|c|c|c|}
\hline \multicolumn{4}{|c|}{ Level of studies } & \multicolumn{4}{|c|}{ Civil Status } \\
\hline & Men & Women & Total & & Men & Women & Total \\
\hline Incomplete primary studies & $36.6 \%$ & $60.4 \%$ & $52.9 \%$ & Single & $11.3 \%$ & $5.2 \%$ & $7.1 \%$ \\
\hline Graduate & $26.8 \%$ & $25.3 \%$ & $25.8 \%$ & Married living with spouse & $62 \%$ & $37.7 \%$ & $45.3 \%$ \\
\hline Mid-level studies & $7 \%$ & $2.6 \%$ & $4 \%$ & Married not living with spouse & $2.8 \%$ & $0.6 \%$ & $1.3 \%$ \\
\hline Higher Education & $14.1 \%$ & $5.2 \%$ & $8 \%$ & Widowed & $14.1 \%$ & $48.7 \%$ & $37.8 \%$ \\
\hline Baccalaureateor PT & $8.5 \%$ & $5.2 \%$ & $6.2 \%$ & Divorced & $8.5 \%$ & $6.5 \%$ & $7.1 \%$ \\
\hline Master & $1.4 \%$ & - & $0.4 \%$ & Other & $1.4 \%$ & $1.3 \%$ & $1.3 \%$ \\
\hline Incomplete thir dlevel studies & $1.4 \%$ & - & $0.4 \%$ & & & & \\
\hline Did not know did not answer & $2.8 \%$ & $0.6 \%$ & $1,3 \%$ & & & & \\
\hline
\end{tabular}




\section{Instruments}

Two questionnaires from the Achenbach System of Empirically Based Assessment (ASEBA) assessment instruments have been used:

The Older Adult Self-Report (OASR) (Achenbach et al., 2004 ) is a self-report for people over 60 years of age, comprising 127 items on a Likert-type scale with three response options where 0 "is not true" and 2 is "very true" and has different cut-off points depending on age, some for 60-75 years and others for above 75 years. It consists of three scales, the psychosocial competencies scale, including friends, partner support, and personal strengths. The empirical syndromes scale, which includes anxiety / depression, worries, somatic complaints, functional impairment, memory / cognition problems, thought problems, irritability / disinhibition and total problems. And the DSM-oriented problem scale, which includes depression, anxiety, somatic complaints, dementia, psychotic and antisocial problems. The Spanish adaptation of the OASR questionnaire (Ezpeleta, 2004) was used, which has identical factors and reliability as the original version $(\alpha=.89)$.

The Older Adult Behavior Checklist (OABCL) questionnaire was also usedto find out the perception of the mental health of the elderly by third parties, (Achenbach et al., 2004) adapted to Spanish (Ezpeleta, 2004), which has the same reliability $(\alpha=.91)$ and factors as the original version. It includes the same information as the OASR questionnaire, but is answered by an external observer, who must maintain a close relationship with the person being assessed for at least some months and is written in the third person.

\section{Procedure}

In 2017 we contacted the General Directorate of People with Disabilities of the Region of Murcia and the Instituto Murciano de Acción Social (Murcia Institute of Social Action) Deputy Director of the Elderly, by phone and by email to request access and gather information from centers for the elderly, day centers and nursing homes in the Region of Murcia. On receiving authorization, we contacted centers wishing to participate in the study. Within the centers, contact persons (workers or volunteers) were designated to visit and administer the questionnaires at the most appropriate times, both for the elderly and their caregivers or direct family members.

Different populations in the Region of Murcia were visited, corresponding to the different health areas of the Murcia Health Service.

Questionnaireswere administered on receiving informed consent from the users of the centers and their families both anonymously and individually. The person interpreted and answered the questionnaire without any type of clarification or semantic assistance from researchers, to avoid tainting or directing answers.

People who took part in this research were over 60 years of age and provided informed consent. Exclusion criteria were: intellectual impairment, severe mental disorder, not providing two sources of information, not having a partner or caregiver, and those with a significant Global Impairment Degree (GDS greater than or equal to 4, previously measured by the day center or residence).

Six participants were excluded who did not provide two sources of information, resulting in the final sample of $n=$ 288.

\section{Data analysis}

The IBM SPSS version 23 program for Windows was used for statistical treatment of data. A descriptive and frequency analysis of the sample was performed and questionnaire reliability was analyzed with Cronbach's $\alpha$ index for the sample of men, women and the total of both questionnaires. The prevalence of clinical range psychological disorders measured by both questionnaires was calculated for both men and women of the total sample and from two age groups (60-75 years, above 76 years).

The Kolmogorov-Smirnov test was used to know if variables to be studied complied with the homogeneity principle and bivariate correlations were made using the Pearson coefficient, as well as mean differences of the problem behaviors based on gender and place of residence using the Student's $t$ test.

No cases in the study sample were excluded from the analysis.

\section{Results}

The reliability indices of the OASR and OABCL indicate acceptable internal consistency, higher in all cases in reports by caregivers and relatives (Table 2).

Table 2

Internal consistency of questionnaires.

\begin{tabular}{ccc}
\hline & OASR Reliability Index & OABCL Reliability Index \\
\hline Men & $\alpha=.486$ & $\alpha=.624$ \\
Women & $\alpha=.503$ & $\alpha=.595$ \\
Mixed & $\alpha=.495$ & $\alpha=.609$ \\
\hline
\end{tabular}

The prevalence of clinical symptoms $(M+1 D T)$ of both questionnaires were calculated for empirical syndromes and DSM equivalences, both for men and women in two age groups, between $60-75$ years and older than 75 years (Table 3). The prevalence range from $40 \%$ in Worries, to $19 \%$ in Memory Problems in OASR, and in OABCL they are between $38 \%$ and $20 \%$ respectively. 
Table 3

Prevalence of Empirical syndromes, DSM scales and psychosocial competencies of clinical range.

\begin{tabular}{|c|c|c|c|c|c|c|c|c|c|c|}
\hline & \multicolumn{4}{|c|}{ Men } & \multicolumn{4}{|c|}{ Women } & \multirow{2}{*}{\multicolumn{2}{|c|}{$\begin{array}{c}\text { Mixed } \\
\text { Total }\end{array}$}} \\
\hline & \multicolumn{2}{|c|}{ 60-75 Years } & \multicolumn{2}{|c|}{$>75$ Years } & \multicolumn{2}{|c|}{ 60-75 Years } & \multicolumn{2}{|c|}{$>75$ Years } & & \\
\hline & OASR & OABCL & OASR & OABCL & OASR & OABCL & OASR & OABCL & OASR & OABCL \\
\hline Anxiety/Depression & 5.7 & 5.7 & 2.7 & 3.1 & 7.4 & 7 & 11.9 & 8.7 & 27.7 & 24.5 \\
\hline Worries & 7.1 & 7.9 & 5.7 & 7.8 & 11.4 & 9.6 & 15.8 & 13.6 & 40 & 38.9 \\
\hline Somatic Complaints & 4.4 & 6.2 & 3.9 & 3.1 & 4.8 & 4.4 & 11.8 & 7.1 & 24.9 & 20.8 \\
\hline Functional impairment & 3.9 & 7.9 & 4.0 & 15.3 & 4.9 & 6.2 & 10.9 & 8.3 & 23.7 & 37.7 \\
\hline Memory problems & 4.0 & 2.7 & 1.3 & 0 & 6.2 & 7.9 & 7.9 & 10.1 & 19.4 & 20.7 \\
\hline Thought Problems & 3.9 & 7.5 & 2.6 & 3.5 & 4.9 & 6.5 & 11.8 & 9.2 & 23.2 & 26.7 \\
\hline Irritibility & 5.3 & 5.7 & 2.2 & 3.5 & 7.5 & 7.5 & 10.5 & 10.1 & 25.5 & 26.8 \\
\hline Depression (DSM) & 4.4 & 5.7 & 3.6 & 2.6 & 4.4 & 5.7 & 10.0 & 9.7 & 22.4 & 23.7 \\
\hline Anxiety (DSM) & 6.5 & 4.9 & 15.8 & 2.2 & 22.3 & 9.7 & 16.2 & 11.4 & 60.8 & 28.2 \\
\hline Somatic problems (DSM) & 3.5 & 5.7 & 3.1 & 4.8 & 4.0 & 4.0 & 12.3 & 7.1 & 22.9 & 21.6 \\
\hline Dementia problems (DSM) & 4.4 & 4,0 & 1.8 & 0 & 4.9 & 9.6 & 7.9 & 7.8 & 19 & 21.4 \\
\hline Psychotic problems (DSM) & 3.9 & 6.2 & 2.2 & 18.8 & 4.4 & 5.7 & 4.0 & 14.5 & 14.5 & 45.2 \\
\hline Anti-social Behavior (DSM) & 2.2 & 4.8 & 3.5 & 1.7 & 7.0 & 5.7 & 7.5 & 10.5 & 20.2 & 22.7 \\
\hline Friends & 4.0 & 4.8 & 4.0 & 3.5 & 8.8 & 10.1 & 15.3 & 14.1 & 32.1 & 32.5 \\
\hline Spouse & 7.0 & 9.2 & 9.7 & 8.3 & 18.0 & 19.7 & 29.8 & 30.2 & 64.5 & 67.4 \\
\hline Strengths & 3.5 & 4.4 & 14.9 & 14.4 & 0.8 & 2.7 & 4.9 & 6.6 & 24.1 & 28.1 \\
\hline
\end{tabular}

Comparisons between OASR and OABCL show information on how older people perceive themselves and are perceived by their family or caregivers. It is observed that in men aged 60-75 years, their family perceives them worse than they perceive themselves in worries, somatic complaints, functional impairment, thought problems and irritability and when men reach more than 75 years, the family perceives them worse in anxiety/depression, worries, functional deterioration, thought problems and irritability. According to DSM anxiety symptomatology, women triple the prevalence rate of men. The two DSM alterations perceived with highest prevalence by caregivers / relatives, by the elderly people themselves, are psychotic and antisocial problems.

Women aged 60 to 75 are perceived with more clinical indicators than what they perceive themselves in memory problems, functional impairment and thought problems. After the age of 75 , their family perceives them worse in memory problems, although they perceive men worse in functional problems. It is observed that in the group of people over 60 to 75 years old, women show the most clinical indicators in all empirical syndromes.

In the group over 75 years old, women show more indicators of anxiety / depression, worries, somatic complaints, functional impairment, memory problems, thought problems and irritability compared to men. These results show a psychopathological worsening of women compared to men as age increases.

Correlations between empirical OASR syndromes and DSM scales (Table 4) were analyzed using the Pearson test, since the Kolmogorov-Smirnov test was not significant. All present significant relationships with scores above $r_{x y}=.230$ and a maximum of $r_{x y}=.902$. An adequate convergence between both scales is observed, where the best relationships are between scales: somatic complaints with somatic problems $\left(r_{x y}=.902\right)$, memory problems with dementia problems $\left(r_{x y}=.888\right)$, irritability with antisocial behavior $\left(r_{x y}=.850\right)$ and anxiety /depression with anxiety problems $\left(r_{x y}=.843\right)$ and depression problems $\left(r_{x y}=.779\right)$.

Correlations between empirical OABCL syndromes and DSM scales (Table 5) show significant relationships with scores above $r_{x y}=.246$ and maximum of $r_{x y}=.922$. An adequate convergence between both scales is observed, where strongest correlations are found between scales: somatic complaints with somatic problems $\left(r_{x y}=.922\right)$, memory problems with dementia problems $\left(r_{x y}=.888\right)$, irritability with antisocial behavior $\left(r_{x y}=.888\right)$, anxiety/depression with depression problems $\left(r_{x y}=.837\right)$ and anxiety problems $\left(r_{x y}=\right.$ $.831)$.

Correlations between OASR empirical syndromes and the OABCL questionnaire (Table 6) were significant, above $r_{x y}=.163$ and maximum of $r_{x y}=.746$. The best correlations are between the analogous scales: functional impairment OASR-OABCL $\left(r_{x y}=.746\right)$, total scale OASR-OABCL $\left(r_{x y}=\right.$ .673) somatic complaints OASR-OABCL $\left(r_{x y}=.656\right)$, irritability OASR-OABCL $\left(r_{x y}=.604\right)$, anxiety / depression OASR-OABCL $\left(r_{x y}=.575\right)$, thought problems OASROABCL $\left(r_{x y}=.566\right)$, worries OASR-OABCL $\left(r_{x y}=.488\right)$, memory problems OASR-OABCL $\left(r_{x y}=.478\right)$. 
Table 4

OASR correlations. Empirical Syndromes- DSM Scales.

\begin{tabular}{|c|c|c|c|c|c|c|c|c|c|c|c|c|c|c|}
\hline & $\mathrm{AD}$ & W & SC & FI & MP & TP & I & Total & DP & $\mathrm{AP}$ & SP & DP & PP & $\mathrm{AB}$ \\
\hline$\overline{A D}$ & 1 & & & & & & & & & & & & & \\
\hline W & $.525^{* *}$ & 1 & & & & & & & & & & & & \\
\hline SC & $.517^{* *}$ & $.497^{* *}$ & 1 & & & & & & & & & & & \\
\hline FI & $.368^{* *}$ & $.330^{* *}$ & $.504^{* *}$ & 1 & & & & & & & & & & \\
\hline MP & $.520^{* *}$ & $.299^{* *}$ & $.397^{* *}$ & $.425^{* *}$ & 1 & & & & & & & & & \\
\hline TP & $.595^{* *}$ & $.383^{* *}$ & $.528^{* *}$ & $.465^{* *}$ & $.410^{* *}$ & 1 & & & & & & & & \\
\hline I & $.528^{* *}$ & $.346^{* *}$ & $.311^{* *}$ & $.286^{* *}$ & $.315^{* *}$ & $.621^{* *}$ & 1 & & & & & & & \\
\hline Total & $.838^{* *}$ & $.631^{* *}$ & $.742^{* *}$ & $.658^{* *}$ & $.644^{* *}$ & $.793^{* *}$ & $.687^{* *}$ & 1 & & & & & & \\
\hline DP & $.779^{* *}$ & $.625^{* *}$ & $.629^{* *}$ & $.611^{* *}$ & $.543^{* *}$ & $.650^{* *}$ & $.513^{* *}$ & $.883^{* *}$ & 1 & & & & & \\
\hline AP & $.843^{* *}$ & $.475^{* *}$ & $.580^{* *}$ & $.270^{* *}$ & $.462^{* *}$ & $.528^{* *}$ & $.475^{* *}$ & $.744^{* *}$ & $.612^{* *}$ & 1 & & & & \\
\hline SP & $.462^{* *}$ & $.526^{* *}$ & $.902^{* *}$ & $.444^{* *}$ & $.316^{* *}$ & $.460^{* *}$ & $.278^{* *}$ & $.666^{* *}$ & $.556^{* *}$ & $.495^{* *}$ & 1 & & & \\
\hline DP & $.464^{* *}$ & $.275^{* *}$ & $.392^{* *}$ & $.562^{* *}$ & $.888^{* *}$ & $.435^{* *}$ & $.344^{* *}$ & $.643^{* *}$ & $.525^{* *}$ & $.414^{* *}$ & $.304^{* *}$ & 1 & & \\
\hline PP & $.430^{* *}$ & $.230^{* *}$ & $.310^{* *}$ & $.240^{* *}$ & $.285^{* *}$ & $.673^{* *}$ & $.626^{* *}$ & $.572^{* *}$ & $.456^{* *}$ & $.350^{* *}$ & $.278^{* *}$ & $.307^{* *}$ & 1 & \\
\hline ASB & $.537^{* *}$ & $.341^{* *}$ & $.284^{* *}$ & $.346^{* *}$ & $.350^{* *}$ & $.625^{* *}$ & $.850^{* *}$ & $.674^{* *}$ & $.529^{* *}$ & $.463^{* *}$ & $.241^{* *}$ & $.403^{* *}$ & $.553^{* *}$ & 1 \\
\hline
\end{tabular}

Note: AD: Anxiety depression; W: Worries; SC: Somatic complaints; FI: Functional impairment; MP: Memory problems; TP: Thought problems; I: Irritablility; DP: Depression problems (DSM); AP: Anxiety problems (DSM); SP: Somatic problems (DSM); DP: Dementia problems (DSM); PP: Psychotic problems (DSM); AB: Antisocial behavior (DSM). ** $p<.01 ; * p<.05$

Table 5. OABCL correlations. Empirical Syndromes- DSM Scales.

\begin{tabular}{|c|c|c|c|c|c|c|c|c|c|c|c|c|c|c|}
\hline & $\mathrm{AD}$ & W & SC & FI & MP & TP & I & Total & DP & $\mathrm{AP}$ & SP & DP & PP & $\mathrm{AB}$ \\
\hline$\overline{\mathrm{AD}}$ & 1 & & & & & & & & & & & & & \\
\hline W & $.529^{* *}$ & 1 & & & & & & & & & & & & \\
\hline SC & $.546^{* *}$ & $.496^{* *}$ & 1 & & & & & & & & & & & \\
\hline FI & $.386^{* *}$ & $.203^{* *}$ & $.393^{* *}$ & 1 & & & & & & & & & & \\
\hline MP & $.441^{* *}$ & $.296^{* *}$ & $.348^{* *}$ & $.425^{* *}$ & 1 & & & & & & & & & \\
\hline TP & $.625^{* *}$ & $.242^{* *}$ & $.459^{* *}$ & $.540^{* *}$ & $.482^{* *}$ & 1 & & & & & & & & \\
\hline I & $.540^{* *}$ & $.297^{* *}$ & $.432^{* *}$ & $.352^{* *}$ & $.313^{* *}$ & .699** & 1 & & & & & & & \\
\hline Total & $.832^{* *}$ & $.537^{* *}$ & $.716^{* *}$ & $.661^{* *}$ & $.615^{* *}$ & $.837^{* *}$ & $.760^{* *}$ & 1 & & & & & & \\
\hline DP & $.837^{* *}$ & $.552^{* *}$ & $.623^{* *}$ & $.608^{* *}$ & $.566^{* *}$ & $.692^{* *}$ & $.512^{* *}$ & $.883^{* *}$ & 1 & & & & & \\
\hline AP & $.831^{* *}$ & $.543^{* *}$ & $.600^{* *}$ & $.283^{* *}$ & $.331^{* *}$ & $.455^{* *}$ & $.515^{* *}$ & $.720^{* *}$ & $.629^{* *}$ & 1 & & & & \\
\hline SP & $.531^{* *}$ & $.513^{* *}$ & $.922^{* *}$ & $.385^{* *}$ & $.310^{* *}$ & $.419^{* *}$ & $.392^{* *}$ & $.677^{* *}$ & $.612^{* *}$ & $.513^{* *}$ & 1 & & & \\
\hline DP & $.391^{* *}$ & $.261^{* *}$ & $.384^{* *}$ & $.592^{* *}$ & $.888^{* *}$ & $.514^{* *}$ & $.349^{* *}$ & $.641^{* *}$ & $.539^{* *}$ & $.335^{* *}$ & $.345^{* *}$ & 1 & & \\
\hline PP & $.483^{* *}$ & .096 & $.317^{* *}$ & $.387^{* *}$ & $.360^{* *}$ & $.794^{* *}$ & $.602^{* *}$ & $.640^{* *}$ & $.490^{* *}$ & $.330^{* *}$ & $.272^{* *}$ & $.351^{* *}$ & 1 & \\
\hline $\mathrm{AB}$ & $.513^{* *}$ & $.246^{* *}$ & $.419^{* *}$ & $.402^{* *}$ & $.368^{* *}$ & $.744^{* *}$ & $.888^{* *}$ & $.749^{* *}$ & $.518^{* *}$ & $.466^{* *}$ & $.401^{* *}$ & $.428^{* *}$ & $.648^{* *}$ & 1 \\
\hline
\end{tabular}

Note: AD: Anxiety depression; W: Worries; SC: Somatic complaints; FI: Functional impairment; MP: Memory problems; TP: Thought problems; I: Irritablility; DP: Depression problems (DSM); AP: Anxiety problems (DSM); SP: Somatic problems (DSM); DP: Dementia problems (DSM); PP: Psychotic problems (DSM); AB: Antisocial behavior (DSM).** $p<.01 ; * p<.05$

Table 6. OASR-OABCL correlations.

\begin{tabular}{|c|c|c|c|c|c|c|c|c|c|c|c|c|c|c|}
\hline & $\mathrm{AD}$ & $\mathrm{W}$ & SC & FI & MP & $\mathrm{TP}$ & I & Total & DP & AP & SP & $\mathrm{DP}$ & $\mathrm{PP}$ & $\mathrm{AB}$ \\
\hline$\overline{\mathrm{AD}}$ & $.575^{* *}$ & $.359^{* *}$ & $.384^{* *}$ & $.228^{* *}$ & $.252^{* *}$ & $.315^{* *}$ & $.374^{* *}$ & $.503^{* *}$ & $.467^{* *}$ & $.510^{* *}$ & $.369^{* *}$ & $.225^{* *}$ & $.221^{* *}$ & $.366^{* *}$ \\
\hline W & $.383^{* *}$ & $.488^{* *}$ & $.393^{* *}$ & $.197^{* *}$ & $.218^{* *}$ & $.284^{* *}$ & $.332^{* *}$ & $.427^{* *}$ & $.369^{* *}$ & $.401^{* *}$ & $.347^{* *}$ & $.209^{* *}$ & $.185^{* *}$ & $.295^{* *}$ \\
\hline SC & $.421^{\text {** }}$ & $.344^{* *}$ & $.656^{* *}$ & $.394^{* *}$ & $.218^{* *}$ & $.423^{* *}$ & $.320^{* *}$ & $.548^{* *}$ & $.494^{* *}$ & $.424^{* *}$ & $.592^{* *}$ & $.237^{* *}$ & $.286^{* *}$ & $.340^{* * *}$ \\
\hline FI & $.303^{* *}$ & $.163^{*}$ & $.332^{* *}$ & $.746^{* *}$ & $.310^{* *}$ & $.399^{* *}$ & $.251^{* *}$ & $.499^{* *}$ & $.505^{* *}$ & $.187^{* *}$ & $.319^{* *}$ & $.379^{* *}$ & $.220^{* *}$ & $.287^{* *}$ \\
\hline MP & $.309^{* *}$ & $.213^{* *}$ & $.283^{* *}$ & $.226^{* *}$ & $.478^{* *}$ & $.227^{* *}$ & $.191^{* *}$ & $.365^{* *}$ & $.353^{* *}$ & $.275^{* *}$ & $.252^{* *}$ & $.394^{* *}$ & $.163^{*}$ & $.237^{* *}$ \\
\hline TP & $.504^{* *}$ & $.225^{* *}$ & $.396^{* *}$ & $.362^{* *}$ & $.253^{* *}$ & $.566^{* *}$ & $.470^{* *}$ & $.573^{* *}$ & $.452^{* *}$ & $.405^{* *}$ & $.373^{* *}$ & $.275^{* *}$ & $.420^{* *}$ & $.481^{* *}$ \\
\hline I & $.417^{* *}$ & $.228^{* *}$ & $.273^{* *}$ & $.203^{* *}$ & $.211^{* *}$ & $.367^{* *}$ & $.604^{* *}$ & $.472^{* *}$ & $.287^{* *}$ & $.423^{* *}$ & $.230^{* *}$ & $.210^{* *}$ & $.325^{* *}$ & $.480^{* * *}$ \\
\hline Total & $.589^{* *}$ & $.390^{* *}$ & $.540^{* *}$ & $.462^{* *}$ & $.367^{* *}$ & $.509^{* *}$ & $.508^{* *}$ & $.673^{* *}$ & $.587^{* *}$ & $.528^{* *}$ & $.495^{* *}$ & $.369^{* *}$ & $.357^{* *}$ & $.495^{* *}$ \\
\hline DP & $.569^{* *}$ & $.333^{* *}$ & $.474^{* *}$ & $.409^{* *}$ & $.282^{* *}$ & $.416^{* *}$ & $.397^{* *}$ & $.582^{* *}$ & $.596^{* *}$ & $.472^{* *}$ & $.430^{* *}$ & $.270^{* *}$ & $.252^{* *}$ & $.389^{* *}$ \\
\hline AP & $.524^{* *}$ & $.392^{* *}$ & $.481^{* *}$ & $.179^{* *}$ & $.272^{* *}$ & $.291^{* *}$ & $.359^{* *}$ & $.498^{* *}$ & $.423^{* *}$ & $.575^{* *}$ & $.449^{* *}$ & $.244^{* *}$ & $.206^{* *}$ & $.356^{* *}$ \\
\hline SP & $.389^{* *}$ & $.338^{* *}$ & $.603^{* *}$ & $.354^{* *}$ & $.228^{* *}$ & $.372^{* *}$ & $.290^{* *}$ & $.508^{* *}$ & $.466^{* *}$ & $.393^{* *}$ & $.582^{* *}$ & $.244^{* * *}$ & $.246^{* *}$ & $.305^{* *}$ \\
\hline DP & $.326^{* *}$ & $.184^{* *}$ & $.289^{* *}$ & $.324^{* *}$ & $.481^{* *}$ & $.311^{* *}$ & $.251^{* *}$ & $.423^{* *}$ & $.398^{* *}$ & $.266^{* *}$ & $.258^{* *}$ & $.475^{* *}$ & $.189^{* *}$ & $.297^{* * *}$ \\
\hline PP & $.293^{* *}$ & .115 & $.234^{* *}$ & $.139^{*}$ & .119 & $.338^{* *}$ & $.405^{* *}$ & $.347^{* *}$ & $.210^{* *}$ & $.217^{* *}$ & $.198^{* *}$ & .094 & $.346^{* *}$ & $.363^{* *}$ \\
\hline $\mathrm{AB}$ & $.405^{* *}$ & $.244^{* *}$ & $.290^{* *}$ & $.241^{* *}$ & $.268^{* *}$ & $.374^{* *}$ & $.481^{* *}$ & $.466^{* *}$ & $.318^{* *}$ & $.380^{* *}$ & $.271^{* *}$ & $.301^{* * *}$ & $.287^{* *}$ & $.471^{* *}$ \\
\hline
\end{tabular}

Note: AD: Anxiety depression; W: Worries; SC: Somatic complaints; FI: Functional impairment; MP: Memory problems; TP: Thought problems; I: Irritablility; DP: Depression problems (DSM); AP: Anxiety problems (DSM); SP: Somatic problems (DSM); DP: Dementia problems (DSM); PP: Psychotic problems (DSM); AB: Antisocial behavior (DSM). ${ }^{* *} p<.01 ; * p<.05$

In the self-report questionnaire (OASR) there are significant differences between men and women in anxiety / de- pression $(t=-2.772, p<.05)$ ( $M$ male: 10.06; $M$ female: 12.88), partner support $(t=3.651, p<.000)$ ( $M$ male: 3.37 ; 
$M$ female: 1.87$)$, personal strengths $(t=-2.956, p<.005)(M$ male: $25.08, M$ female: 27.75$)$, DSM depression problems $(t$ $=-1.971, p<.05)(M$ male: 8.37 ; $M$ female: 10$)$, DSM anxiety problems $(t=-2.571, p<.05)$ ( $M$ male: $5.17 ; M$ female: $6.58)$, and problems DSM psychotic $(t=2.171, p<.05)(M$ male: $1.44 ; M$ female: 0.98$)$.

In the family/caregiver questionnaire (OABCL) there are significant differences between men and women with functional impairment $(t=1.997, \mathrm{p}<.05)(M$ male: $7.08 ; M$ female: 5.58), thought problems $(t=2.199, p<.05)$ ( $M$ male: 6.38; $M$ female: 4.88$)$, irritability $(t=3.270, p<.005)(M$ male: $11.48 ; M$ female: 8.36$)$, partner support $(t=4.272, p<$ $.000)$ ( $M$ male: 1.80 ; $M$ female: 0.19$)$, DSM psychotic problems $(t=2.828, p<.005$ ) (male: 2.13; female: 1.29), and DSM antisocial personality $(t=2.188, p<.05)$ ( $M$ male: 4.79; $M$ female: 3.84).

As for differences between living at home or in residence, the OASR questionnaire found significant differences in somatic complaints $(t=-4.381, p<.000)$ ( $M$ home: 5.62; $M$ residence: 8.71$)$, functional impairment $(t=-3.324, p<$ $.005)$ ( $M$ home: $5.62 ; M$ residence: 8.71$)$, other problems $(t=$ $-2.136, p<.05)$ ( $M$ home: $5.02 ; M$ residence: 6.06$)$, total problems $(t=-2,211, p<.05)$ ( $M$ home: $55.41 ; M$ residence: 63.59), personal strengths $(t=5.279, p<.000)$ ( $M$ home: 28.60; $M$ residence: 24.23$)$, and DSM somatic problems $(t=$ -3.880, $p<.000$ ) ( $M$ home: 3.24; $M$ residence: 4.95 ).

In the OASR questionnaire, significant differences were found in functional impairment $(t=-3.011, p<.005)$ ( $M$ home: $5.22 ; M$ residence: 7.37$)$, thought problems $(t=$ 3.675, $p<.000)$ ( $M$ home: $4.45 ; M$ residence: 6.79$)$, other problems $(t=-3.106, p<.005)$ ( $M$ home: $4.67 ; M$ residence: 6.24), total problems $(t=-2.006, p<.05)$ ( $M$ home: $54.11 ; M$ residence: 62.07$)$, personal strengths $(t=5.633, p<.000)(M$ home: 27.39; $M$ residence: 21.97), DSM depression problems $(t=-2.520, p<.05)(M$ home: $8.22 ; M$ residence: 10.21$)$ and DSM psychotic problems $(t=-2.978, p<.005)$ ( $M$ home: 1.23; $M$ residence: 2.07 ).

On analyzing the interaction between sex and residence of the univariate models, this was only significant in the OASR personal strengths variable $(F=4.724, p<.05 ; \mathrm{R} 2=$ .147) ( $M$ male-household: 25.825; $M$ male-residence: 24,129 ; $M$ woman-house: 29,735; $M$ woman-residence: 24,286$)$.

\section{Discussion}

In general terms, more psychopathological problems, especially of the anxious-depressive type, have been found in women, people who live in residences and as age increases. These results concur with similar studies to date (Ausín et al., 2017; Black et al., 2019; Charney et al., 2003; Damián et al., 2012; Gázquez-Linares et al., 2008; Kronfly-Rubiano et al., 2015; Ritchie et al., 2004) and may be due to the increased vulnerability of older people as age increases (Sajjad et al., 2017), to the greater psychosocial risk it poses for older people in residences (Wang et al., 2019) and by the differential affectation of psychopathology based on gender (Geulayov et al., 2018) that more seriously affects women, possibly owing to gender socialization processes, present throughout the people's life cycle.

More specifically, being a woman is associated with a higher risk of suffering psychopathology, since they score significantly higher than men in all variables, except for psychotic problems (DSM). Likewise, women score higher than men in variables related to social support, relationship with the spouse, number of friends and personal strengths. For their part, both men and their informant perceive support from their spouse (wife), while older women do not perceive support from their husbands, nor do external informants believe their husbands provide them with support. although women perceive themselves better in personal strengths. It is also seen that people who live in residences are and are perceived worse psychologically than those who reside at home.

We believe that these results can be partly explained by factors such as financial difficulties, which can worsen in older people once they retire; loss of self-perceived physical health in the elderly associated with mortality (Sajjad et al., 2017); loss of social support network, that is, the death of close friends or sporadic contact with family members (Wang et al., 2019), particularly in the area of residences; mourning for the loss of a spouse, which especially affects women as they generally live longer than men (Förster et al., 2019) and marriage is considered a protective factor against depressive symptoms (Kim et al. , 2020); Life in urban settings, since in rural settings the mental health demands of this group are generally better served (Roheger et al., 2019). The comorbidity of mental health problems with other problems, whether organic or mental, that generally affect women more severely than men (Geulayov et al., 2018), have been shown in various research as predictive factors of psychopathology in older people (Baiyewu et al., 2015; Curran et al., 2019; Sengupta et al., 2015; Yadav et al., 2020).

As with other research (Achenbach, et al., 2005), a certain disparity is observed in the perception of psychopathological problems between older people and their families. In the age range of $60-75$ years, the family generally perceives them worse than they perceive themselves, but when over 75 years old, the elderly perceive themselves worse than their families. However, there is an adequate correlation between the self-reported questionnaire and that reported by third parties, although with some differences, which makes it possible to consider that assessment in the elderly population is more complete when multi-informant data are collected. Furthermore, in spite of the scarcity of instruments which assess mental health in older people from a multi-informant perspective (Mindt, et al. 2019), the good correlation observed between questionnaires can be explained as the Achenbach questionnaires were developed to gather information from the multi-informant perspective and as with numerous research (Brigidi et al., 2010; de Oliveira et al., 2017; Ivanova et al., 2017; Ivanova et al., 2020), there is a good correlation between the different syndromes and scales of both questionnaires and in different cultures. 
Other research has found that economic crises and financial difficulties increase depressive and anxiety disorders (Baiyewu et al., 2015). During the 2008 financial crisis in our country, older people significantly increased problems of major depression $(19.4 \%)$, dysthymia $(10.8 \%)$, generalized anxiety (8.4\%), panic attacks (6.4\%), somatoform disorders $(7.2 \%)$, alcohol dependence (4.6\%) and alcohol abuse $(2.4 \%)$. Furthermore, the prevalence of mental disorders went up by $21 \%$ in women and $21.7 \%$ in men (Gil et al., 2014). The current pandemic and the economic crisis caused by COVID-19 in Spain pose a risk for mental health; as some studies already point out, the psychological and emotional health of the elderly is being affected and the effects are similar to post-traumatic stress disorder (PinazoHernandis, 2020). In this study, anxiety-depressive problems are seen to be most prevalent in the elderly population, therefore it is to be expected that this prevalence will increase following the COVID-19 pandemic. Even so, some studies indicate that the elderly are the the age group which has suffered the least psychological distress and anxietydepression during confinement (Losada-Baltar et al., 2020), the long-term effects of confinement and the financial situation of older people have yet to be studied and this work can serve as a reference to observe perceived discrepancies in mental health prior to the pandemic.

We stress that incidental sampling used is the main limitation of the study. Another important limitation is the low internal consistency found in the questionnaires for this sample, compared to other international studies (Achenbach et al., 2004; Ivanova et al., 2017). This discrepancy could be due to incidental sampling and the fact that the sample focuses exclusively on the Region of Murcia. In future research, these data can serve as a comparative point to ana-

\section{References}

Achenbach, T. M., Newhouse, P.A., \& Rescorla, L. A. (2004). Manual for the ASEBA Older Adult Forms \& Profiles. Burlington, VT: University of Vermont, Research Center for Children, Youth, \& Families.

Achenbach, T. M., Krukowski, R. A., Dumenci, L., Ivanova, M. Y. (2005). Assessment of adult psychopathology: meta-analyses and implications of cross-informant correlations. PsychologicalBulletin, 131(3), 361-382. doi: 10.1037/0033-2909.131.3.361.

Ausín, B., Muñoz, M., Santos-Olmo, A. B., Pérez-Santos, E., \& Castellanos, M. A. (2017). Prevalence of Mental Disorders in the Elderly in the Community of Madrid: Results of the Mentdis-ICF65+ Study. Spanish Journal of Psychology, 20, 1-11. doi: 10.1017/sjp.2017.3.

Baiyewu, O., Yusuf, A. J., \&Ogundele, A. (2015). Depression in elderly people living in rural Nigeria and its association with perceived health, poverty, and social network. International Psychogeriatrics, 27(12), 20092015. doi: 10.1017/S1041610215001088.

Black, C. M., Ambegaonkar, B. M., Pike, J., Jones, E., Husbands, J., \&Khandker, R. K. (2019). The Diagnostic Pathway from Cognitive Impairment to Dementia in Japan: Quantification Using Real-World Data. Alzheimer Disease and Associated Disorders, 33(4): 346-353. doi: 10.1097/WAD.0000000000000322.

Brigidi, B. D., Achenbach, T. M., Dumenci, L., \& Newhouse, P. A. (2010). Broad spectrum assessment of psychopathology and adaptive functioning with the Older Adult Behavior Checklist: a validation and diagnostic discrimination study. International Journal of Geriatric Psychiatry, 25, 1177-1185. doi: 10.1002/gps.2459. lyze the psychological effects of the pandemic on the elderly in our country and it should be assessed whether psychosocial competencies need another more specific instrument to be measured. The data broaden and update psychopathology research in older people, including data from residents of various municipalities. Finally, it is concluded that it is essential to know the state of people over 65 years old as regards their mental health, in order to develop better health care programs oriented toward the specific problems of this age group. Different perceptions of mental health have been observed among older people and their families, which worsen with increasing age, psychosocial risk situation and sex. This reflects the need to develop specific treatment protocols for each gender and psychosocial risk situation, which include family members of reference, in order to meet the differential mental health needs of the elderly.

\section{Conclusions}

This study highlights the different mental health characteristics of the elderly based on age range, gender and the informant. Thus, we conclude it necessary to expand studies on mental health problems in that long period called old age, and that it actually seems to have several different stages. A more exhaustive analysis and with larger samples seems essential, given the increase in life expectancy. For this reason, the need to generate psychosocial care and attention programs increases, since being in a residence is linked to more psychological problems and financial difficulties. Likewise, specific mental health protocols are needed taking into account differences in age group, sex, and socioeconomic conditions.

Charney, D. S., Reynolds, C. F. , Lewis, L., Lebowitz, S.T., Lexopoulos, G. S., Blazer, D. S., ...Y Young R. C. (2003). Depression and bipolar support Alliance consensus statement on the unmet needs in diagnosis and treatment of mood disorders in late life. Archives of General Psychiatry, 60(7), 664-672. doi: 10.1001/archpsyc.60.7.664.

Cisneros G. E., \&Ausín B. (2018) Prevalencia de los trastornos de ansiedad en las personas mayores de 65 años. Una revisión sistemática. Revista Española de Geriatría y Gerontología, 54(1), 34-48. doi: 10.1016/j.regg.2018.05.009.

Curran, E., Rosato, M., Cooper, J., Mc Garrigle, C .A., \&Leavey, G. (2019). Symptom profiles of late-life anxiety and depression: The influence of migration, religion and loneliness. Depression and Anxiety, 39(9), 824-833. doi: 10.1002/da.22893.

Damián, J., de Pedro-Cuesta, J., Almazán, J., Comín-Comín, M., Quintanilla, M. A., \& Lobo, A. (2012). Depressive symptoms and associated factors in an older Spanish population positively screened for disability. International Journal of Geriatric Psychiatry, 28(7), 745-755. doi: 10.1002/gps.3886.

de Oliveira, C.R., Paloski, L.H., Farina, M., Gonzatti, V., Cunha, A.M., de Oliveira, M.Z.,..\&QQuarti-Irigaray, T. (2017). Older adult self reportconstruct and criterion validity evidence for Brazilian elderly. Anales de psicología, 33(2), 277-282. doi: 10.6018/analesps.33.2.236781.

Ezpeleta, L. (2004). Inventario del comportamiento de adultos de 60 a 90+ años. Universidad Autónoma de Barcelona, Unitat d' Epidemiologia i Diagnòstic en Psicopatología del Desenvolupament. 
Förster, F., Pabst, A., Stein, J., Röhr, S., Löbner, M., Heser, K.,...\& RiedelHeller, S.G. (2019). Are older men more vulnerable to depression than women after losing their spouse? Evidence from three German old-age cohorts (AgeDifferent.de platform). Journal of Affective Disorders, 256: 650-657. doi: 10.1016/j.jad.2019.06.047.

Gázquez-Linares, J. J., Pérez-Fuentes, M. C., Lucas-Acién, F., y YusteRosell, N. (2008). Prevalencia de los trastornos mentales en la población mayor. Anales de Psicología, 24(2), 327-333. Recuperado de: https://revistas.um.es/analesps/article/view/42881.

Geulayov, G., Novikov, I., Dankner, D., \&Dankner, R. (2018). Symptoms of depression and anxiety and 11-year all-cause mortality in men and women undergoing coronary artery bypass graft (CABG) surgery. Journal of Psychosomatic Research, 105: 106-114. doi: 10.1016/j.jpsychores.2017.11.017.

Gil, M., García-Campayo, J., y Roca, M. (2014). Crisis económica y salud mental. Informe SESPAS 2014. Gaceta Sanitaria, 28(1), 104-108. doi: 10.1016/j.gaceta.2014.02.005

HoangLan, N., \&ThiThuThuy, N. (2020). Depression among ethnic minority elderly in the Central Highlands, Vietnam. Health Psychology Open, 7(2). doi: https://doi.org/10.1177/2055102920967236.

Ivanova, M. Y., Achenbach, T. M., Leite, M., Almeida, V., Caldas, C., Turner, L., \& Dumas, J. A. (2017). Empirically derived dimensional syndromes of self-reported psychopathology: Cross-cultural comparisons of Portuguese and US elders. International Journal of Geriatric Psychiatry, 33(5), 695-702. doi:10.1002/gps.4840.

Ivanova, M. Y., Achenbach, T. M., Rescorla, L. A., Turner, L. V., Dumas, J. A., Almeida, V.,...\&Zasepa, E. (2020). The generalizability of Older Adult Self-Report (OASR) syndromes of psychopathology across 20 societies. International Journal of Geriatric Psychiatry, 35(5). doi:10.1002/gps.5268.

Kim, H., Cho, J., Isehunwa, O., Noh, J., Noh, Y., Oh, S. S., Koh, S. -B., \& Kim, C. (2020). Marriage as a social tie in the relation of depressive symptoms attributable to air pollution exposure among the elderly. Journal of AffectiveDissorders, 272: 125-131. doi: 10.1016/j.jad.2020.04.059.

Kronfly-Rubiano, E., Rivilla-Frias, D., Ortega-Abarca, I., VillanuevaVillanueva, M., Beltrán-Martínez, E., Comellas-Villalba, M.,...\& Barranco-Oliver, L. (2015). Riesgo de depresión en personas de 75 años o más, valoración geriátrica integral y factores de vulnerabilidad asociados en Atención Primaria. Atención Primaria, 47(10), 616-625. doi: 10.1016/j.aprim.2014.09.012.

Lang, G., Resch, K., Hofer, K., Braddick, F., \& Gabilondo, A. (2010). Background document for the Thematic Conference on Mental Health and WellBeing among Older. Luxembourg: EuropeanCommunities, 2010.

Losada-Baltar, A., Márquez-González, M., Jiménez-Gonzalo, L., del Sequeros Pedroso-Chaparro, M., Gallego-Alberto, L., \&FernandesPires, J. (2020). Diferencias en función de la edad y la autopercepción del envejecimiento en ansiedad, tristeza, soledad y sintomatología comórbida ansioso-depresiva durante el confinamiento por la COVID19. Revista Española de Geriatría y Gerontología, 55(5), 272-278. doi: 10.1016/j.regg.2020.05.005.

Mindt, M. R., Arentoft, A., Coulehan, K., Summers, A. C., Tureson, K. Aghvinian, M., y Byrd, D. A. (2019). Neuropsychological evalua-tion of culturally/linguistically diverse older adults. En L. Ravdin, H. Katzen(Eds.), Handbook on the Neuropsychology of Aging and Dementia. ClinicalHandbooks in Neuropsychology(pp. 25-48). Springer.

Organización Mundial de la Salud. (2015, 2017). Informe Mundial sobre el Envejecimiento y la Salud. Organización Mundial de la Salud. Recuperado de: https://www.who.int/ageing/publications/world-report-2015/es/.

Pinazo-Hernandis, S. (2020). Impacto psicosocial de la COVID-19 en las personas mayores: problemas y retos. Revista Española de Geriatría y Gerontología, 55(5), 249-252. doi: 10.1016/j.regg.2020.05.006.

Ritchie, K., Artero, S., Beluche, I., Ancelin, M.L., Mann, A., Dupuy, A. M. \&Boulenger, J. P. (2004). Prevalence of DSM-IV psychiatric disorder in the French elderly population. The British Journal of Psychiatry, 184(2), 147-152. doi: 10.1192/bjp.184.2.147.

Roheger, M., Eriksdotter, M., Westling, K., Kalbe, E., \& Garcia-Ptacek, S. (2019). Basic Diagnostic Work-Up Is More Complete in Rural than in Urban Areas for Patients with Dementia: Results of a Swedish Dementia Registry Study. Journal of Alybeimer's Disease, 69(2), 455-462. doi: 10.3233/JAD-190017.

Sajjad, A., Freak-Poli, R. L., Hofman, A., Roza, S.J., Ikram, M. A., \&Tiemeier, H. (2017). Subjective measures of health and all-cause mortality - The Rotterdam Study. Psychological Medicine, 47(11), 1971 1980. doi: 10.1017/S0033291717000381.

Sengupta, P., \& Benjamin, A. I. (2015). Prevalence of depression and associated risk factors among the elderly in urban and rural field practice areas of a tertiary care institution in Ludhiana. Indian Journal of Public Health, 59(1), 3-8. doi: 10.4103/0019-557X.152845.

Valdés M., González J. A., Abdulkadir M. S. (2017). Prevalencia de depresión y factores de riesgo asociados a deterioro cognitivo en adultos mayores.Revista Cubana de Medicina General Integral, 33(4). Recuperado http://scielo.sld.cu/scielo.php?script=sci arttext\&pid=S086421252017000400001\&lng=es\&tlng=es.

Wang, L., Liu, W., Liang, Y., \& Wei, Y. (2019). Mental health and depressive feeling of empty-nest elderly people in China. American Journal of Health Behavior, 43(6), 1171-1185. doi: 10.5993/AJHB.43.6.14.

Yadav, U., Thapa, T. B., Mistry, S. K., Pokhrel, R., \& Harris, M. F. (2020) Socio-demographic characteristics, lifestyle factors, multi-morbid conditions and depressive symptoms among Nepalese older adults. Psychiatry, 20, 261-270. doi: 10.21203/rs.3.rs-16333/v1. 